Check for updates

Cite this: RSC Adv., 2020, 10, 6953

Received 5th December 2019

Accepted 16th January 2020

DOI: 10.1039/c9ra10191h

rsc.li/rsc-advances

\title{
Synthesis, characterization, and properties of a novel aromatic ester-based polybenzoxazine
}

\begin{abstract}
Chunli Zhu, Xing Gao, Weixi Fan and Xiaofen Fu (D) *
Polybenzoxazines with molecular design flexibility have excellent properties by using suitable raw materials. A new benzoxazine monomer terephthalic acid bis-[2-(6-methyl-4H-benzo[e][1,3]oxazin-3-yl)]ethyl ester (TMBE) with bis-ester groups has been synthesized from the simple esterification reaction of terephthaloyl chloride and 2-(6-methyl-4H-benzo[e][1,3]oxazin-3-yl)-ethanol (MB-OH). The chemical structure of TMBE was characterized by Fourier transform infrared spectroscopy (FT-IR) and nuclear magnetic resonance spectroscopy $\left({ }^{1} \mathrm{H}-\mathrm{NMR},{ }^{13} \mathrm{C}-\mathrm{NMR}\right)$. Polymerization behavior of TMBE was studied by differential scanning calorimetry (DSC) and FT-IR after each cure stage. The cross-linked polybenzoxazine (PTMBE) gave a transparent film through the thermal casting method. The dynamic mechanical analysis of PTMBE showed that the $T_{\mathrm{g}}$ was $110{ }^{\circ} \mathrm{C}$. Thermogravimetric analysis reveals better thermal stability as evidenced by the $5 \%$ and $10 \%$ weight-loss temperatures $\left(T_{\mathrm{d} 5}\right.$ and $\left.T_{\mathrm{d} 10}\right)$ of PTMBE, which were 263 and $289{ }^{\circ} \mathrm{C}$, respectively, with a char yield of $27 \%$ at $800{ }^{\circ} \mathrm{C}$. The tensile test of the film revealed that the elongation at break was up to $14.2 \%$.
\end{abstract}

\section{Introduction}

As a new phenolic-type resin, polybenzoxazines possess attractive properties, such as high glass transition temperature, ${ }^{\mathbf{1 , 2}}$ flame retardancy, ${ }^{3}$ low water absorption, ${ }^{4}$ and low cost. ${ }^{5}$ They are applied to the field of halogen-free flame retardant laminates, vacuum pump rotors, printed circuit boards, friction materials, composites, and other fields. ${ }^{6,7}$ Nevertheless, inherent brittleness of polybenzoxazines, especially in aromatic polybenzoxazines, limits their further development in the chemical industry.

There are generally three reported approaches to improve the toughness of polybenzoxazines. The first approach is introducing rubber, ${ }^{\mathbf{8} 9}$ the flexible heat-resistant linear polymer ${ }^{\mathbf{1 0 - 1 4}}$ into resins as the toughening agent to improve toughness. The second approach is designing inherently tough benzoxazine monomers containing soft segments to afford tough polybenzoxazines. ${ }^{15,16}$ The third approach is the toughening of polybenzoxazines by inorganic nanoparticles. ${ }^{17-19}$ Among them, the designing of inherently tough benzoxazine monomers and polybenzoxazines prepolymers was a significant approach to improve the flexibility of polybenzoxazines from the molecular level, and to increase the degree of chemical crosslinking between the two phases.

The tough benzoxazine monomers were synthesized, including monofunctional and difunctional benzoxazines from available phenols containing flexible groups, primary amines and formaldehyde. ${ }^{\mathbf{4} 20-23}$ These monomers improve the

School of Chemistry and Biological Engineering, Qilu Institute of Technology, Jinan, 250200, P. R. China. E-mail: i40597087qiaoqia3@163.com flexibility of polybenzoxazines with dramatically scarifying their heat resistance. Therefore, some main-chain type polybenzoxazines $^{\mathbf{2 4 , 2 5}}$ were synthesized by Mannich reaction with polyether diamines of different molecular weights or PDMS with different molecular weights for the diamine terminal, bisphenol A, and formaldehyde. Such high-molecular-weight prepolymers exhibited significantly improved toughness due to the soft segments and generated a high cross-linking degree due to the polybenzoxazine component.

The other approach to improve toughness is indirectly preparing of polybenzoxazine prepolymers using polyesterification, ${ }^{\mathbf{1 4}}$ coupling reactions, alternating copolymerization of donor-acceptor monomers, ${ }^{26}$ Diels-Alder reaction, ${ }^{27}$ polyetherification, $^{28} \quad$ hydrosilylation $^{29} \quad$ These synthetic approaches also necessarily yield high-performance polybenzoxazines with improved toughness. The novel polyesters were synthesized from the polycondensation reaction of bisbenzoxazine-diol, pyromellitic dianhydride, and 4,4'-(hexafluoroisopropylidene)diphthalic anhydride. ${ }^{\mathbf{1 4}}$ The molecular weights of polyesters were in the range of 5800-7000 Da with benzoxazine moieties in the main chain exhibited high flexibility induced by the soft pentyl and esters groups and comparable thermal stability concerning low molar mass analogous. Aydogan ${ }^{29}$ prepared polysiloxanes containing benzoxazine units in the main chain by hydrosilylation of 1,1,3,3tetramethyldisiloxane and diallyl functional benzoxazines. To further improve its flexibility, polysiloxanes chain was extended by the reaction of poly (bisbenzoxazinedimethylsiloxane)s and octamethyl-cyclotetrasiloxane in the presence of tetrabutylammonium hydroxide as a catalyst. 
Based on this idea, our work presents a facile route for synthesizing high-purity aromatic benzoxazine containing bisester groups. First, 2-(6-methyl-4H-benzo[e][1,3]oxazin-3-yl)ethanol (MB-OH) was synthesized from formaldehyde solution (37\%), ethanolamine, and $p$-cresol. Then, terephthalic acid bis[2-(6-methyl-4H-benzo[e][1,3] oxazin-3-yl)]ethyl ester (TMBE) with bis-ester groups has been synthesized from the simple esterification reaction of $\mathbf{M B}-\mathbf{O H}$ and terephthaloyl chloride. The crosslinked polybenzoxazine (PTMBE) gave transparent flexible film through the thermal casting method. The thermal and mechanical properties of aromatic ester-based polybenzoxazine were studied and compared with respect to polybenzoxazines analogous.

\section{Material and methods}

\subsection{Materials}

Potassium hydroxide, $p$-cresol (98\%) were purchased from Sinopharm Chemical Reagent Co., Ltd. 2-Aminoethanol, dioxane, triethylamine $\left(\mathrm{Et}_{3} \mathrm{~N}\right)$, methylene chloride was obtained from Tianjin Fu Jin Fine Chemical Co., Ltd. Formaldehyde (37 wt\% in water), terephthaloyl chloride, $n$-hexane was used as received. Methylene chloride used after distillation.

\subsection{Synthesis of MB-OH}

MB-OH was synthesized according to the literature. ${ }^{12}$ A suspension of paraformaldehyde $(15.3 \mathrm{~mL}, 210 \mathrm{mmol}), 30 \mathrm{~mL} \mathrm{1,4-}$ dioxane were added to a $250 \mathrm{~mL}$ three-neck flask in an ice bath. Then 2-aminoethanol $(6.0 \mathrm{~mL}, 100 \mathrm{mmol})$ was added drop-wise to the system. The mixture stirred at room temperature for about $30 \mathrm{~min}$. After adding $p$-cresol (10.6 mL, $100 \mathrm{mmol})$, the temperature was gradually increased to $70{ }^{\circ} \mathrm{C}$, and stirring was continued for another $3.5 \mathrm{~h}$. A yellowish viscous fluid was obtained after removing the solvent through a rotary evaporator. Then the viscous liquid was dissolved in dichloromethane, washed with $1 \mathrm{~L}$ of $0.1 \mathrm{~N}$ aqueous $\mathrm{KOH}$ and finally three times with $1 \mathrm{~L}$ of distilled water. The methylene chloride solution was dried with $\mathrm{MgSO}_{4}$, filtered, and concentrated under vacuum to afford crude product. The crude product was recrystallized with $n$-hexane to give pure white solid of $\mathbf{M B}-\mathbf{O H}(9.53 \mathrm{~g}, 51 \%)$.

${ }^{1} \mathrm{H}$ NMR $\left(\mathrm{CDCl}_{3}, 300 \mathrm{MHz}, \delta\right): 3.98 \mathrm{ppm}\left(\mathrm{s}, \mathrm{Ar}-{ }^{*} \mathrm{CH}_{2}-\mathrm{N}\right)$, $4.85 \mathrm{ppm}\left(\mathrm{s}, \mathrm{O}-{ }^{*} \mathrm{CH}_{2}-\mathrm{N}\right), 2.95 \mathrm{ppm}\left(\mathrm{t}, \mathrm{N}-{ }^{*} \mathrm{CH}_{2}-\mathrm{C}\right), 3.69 \mathrm{ppm}(\mathrm{t}$, $\left.\mathrm{C}-{ }^{*} \mathrm{CH}_{2}-\mathrm{O}\right), 2.24 \mathrm{ppm}\left(\mathrm{s}, \mathrm{Ph}-{ }^{*} \mathrm{CH}_{3}\right)$.

FTIR (KBr) $\nu$ : $1034 \mathrm{~cm}^{-1}$ (C-O-C symmetric stretching), $1232 \mathrm{~cm}^{-1}$ (C-O-C asymmetric stretching), $1502 \mathrm{~cm}^{-1}$ (trisubstituted benzene ring), $940 \mathrm{~cm}^{-1}$ (oxazine ring).

\subsection{Synthesis of TMBE}

Into a $100 \mathrm{~mL}$ dry round-bottom flask equipped with a calcium chloride drying tube, $20 \mathrm{~mL}$ dry methylene chloride, $\mathbf{M B}-\mathbf{O H}$ $(1.9 \mathrm{~g}, 10 \mathrm{mmol})$, triethylamine $(1.7 \mathrm{~mL}, 1.4 \mathrm{mmol})$ were added and mixed at room temperature for about $30 \mathrm{~min}$. Then terephthaloyl chloride $(1.0 \mathrm{~mL}, 5.0 \mathrm{mmol})$ was added at $5{ }^{\circ} \mathrm{C}$. The mixtures were stirred at room temperature for $2 \mathrm{~d}$ and kept refluxing for $4 \mathrm{~h}$. A yellow transparent solution was obtained after cooling to room temperature. The solution was washed with $1 \mathrm{~L}$ of $0.5 \mathrm{~N}$ aqueous $\mathrm{NaOH}$ and finally three times with $1 \mathrm{~L}$ of distilled water. The methylene chloride solution was dried with $\mathrm{MgSO}_{4}$, filtered, and concentrated under vacuum to afford crude product (1.6 g, yield: 61\%). The product was purified by chromatography $\left(v_{\text {methylene chloride }}: v_{\text {ethyl acetate }}=2: 1\right)$ to afford white power solid.

${ }^{1} \mathrm{H}$ NMR $\left(\mathrm{CDCl}_{3}, 300 \mathrm{MHz}, \delta\right): 4.05 \mathrm{ppm}\left(\mathrm{s}, \mathrm{Ar}-* \mathrm{CH}_{2}-\mathrm{N}\right)$, $4.88 \mathrm{ppm}\left(\mathrm{s}, \mathrm{O}-{ }^{*} \mathrm{CH}_{2}-\mathrm{N}\right), 3.18 \mathrm{ppm}\left(\mathrm{t}, \mathrm{N}-{ }^{*} \mathrm{CH}_{2}-\mathrm{C}\right), 4.52 \mathrm{ppm}(\mathrm{t}$, $\mathrm{C}-{ }^{*} \mathrm{CH}_{2}-\mathrm{O}$ ), $2.27 \mathrm{ppm}\left(\mathrm{s}, \mathrm{Ph}-{ }^{*} \mathrm{CH}_{3}\right)$.

${ }^{13} \mathrm{C}$ NMR $\left(\mathrm{CDCl}_{3}, 300 \mathrm{MHz}, \delta\right): 50.70 \mathrm{ppm}\left(\mathrm{Ar}-{ }^{*} \mathrm{CH}_{2}-\mathrm{N}\right)$, $82.85 \mathrm{ppm}\left(\mathrm{O}-{ }^{*} \mathrm{CH}_{2}-\mathrm{N}\right), 50.38 \mathrm{ppm}\left(\mathrm{N}-{ }^{*} \mathrm{CH}_{2}-\mathrm{C}\right), 63.65 \mathrm{ppm}(\mathrm{C}-$ $\left.{ }^{*} \mathrm{CH}_{2}-\mathrm{O}\right), 18.30 \mathrm{ppm}\left(\mathrm{Ph}-{ }^{*} \mathrm{CH}_{3}\right), 165.71 \mathrm{ppm}(\mathrm{O}-\mathrm{C} *=\mathrm{O})$.

FTIR (KBr) $\nu: 1019 \mathrm{~cm}^{-1}$ (C-O-C symmetric stretching), $1277 \mathrm{~cm}^{-1}$ (C-O-C asymmetric stretching), $1506 \mathrm{~cm}^{-1}$ (trisubstituted benzene ring), $932 \mathrm{~cm}^{-1}$ (oxazine ring), $1720 \mathrm{~cm}^{-1}(\mathrm{C}=$ O stretching).

\subsection{Polymerization of TMBE}

The amount of TMBE was melted, stirred and transferred to a rectangular aluminum foil mold and then cured at $120^{\circ} \mathrm{C} / 2 \mathrm{~h}$, $140{ }^{\circ} \mathrm{C} / 2 \mathrm{~h}, 160{ }^{\circ} \mathrm{C} / 2 \mathrm{~h}, 180{ }^{\circ} \mathrm{C} / 2.5 \mathrm{~h}$ in an air-circulating oven. After that, samples were allowed to cool slowly to room temperature to be tested.

\subsection{Characterizations}

FTIR spectra were obtained with Bruker Tensor 27 FTIR spectrometer (Bruker, GM) in which samples were preparing as $\mathrm{KBr}$ pellets. ${ }^{1} \mathrm{H}-\mathrm{NMR}$ and ${ }^{13} \mathrm{C}-\mathrm{NMR}$ spectra were recorded on a Bruker Avance 300 instrument (Bruker) using $\mathrm{CDCl}_{3}$ as the solvent and TMS as the internal standard. Differential scanning calorimetry (DSC) was conducted using a DSC SP instrument (Rheometric Scientific) at a heating rate of $10{ }^{\circ} \mathrm{C} \mathrm{min}^{-1}$ under nitrogen. Thermogravimetric analysis (TGA) was performed on a TGA/DSC STARe System instrument (Mettler-Toledo) at a heating rate of $10{ }^{\circ} \mathrm{C} \mathrm{min}{ }^{-1}$ under $\mathrm{N}_{2}$ atmosphere. The gas

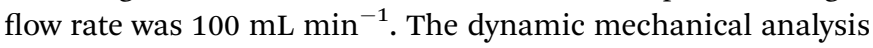
(DMA) of samples was carried out using a Mettler-Toledo DMA/ SDTA861e instrument (Mettler-Toledo). The specimen with dimensions of approximately $3.00 \times 2.20 \times 0.8 \mathrm{~mm}^{3}$ was tested by a shear mode at $1 \mathrm{~Hz}$ in the temperature range of $30-200{ }^{\circ} \mathrm{C}$ at a heating rate of $3{ }^{\circ} \mathrm{C} \mathrm{min}^{-1}$. Tensile measurement were also recorded with Material Testing Machine Model UTM5105 at a crosshead speed of $1 \mathrm{~mm} \mathrm{~min}^{-1}$. Each sample with a dimension of approximately $20.0 \times 5.0 \times 1.0 \mathrm{~mm}^{3}$ was tested from an average of at least 5 tests.

\section{Results and discussion}

\subsection{Preparation of TMBE and its polymer}

Scheme 1 illustrates our strategy for the preparation of TMBE and PTMBE. First, according to reference, we synthesized containing hydroxyl benzoxazine (MB-OH). Second, using triethylamine as deacid reagent, dry dichloromethane as solvent, TMBE was obtained via the esterification reaction of $\mathbf{M B}-\mathbf{O H}$ and terephthaloyl chloride at a molar ratio of $2: 1$. TMBE was easily soluble in common low-boiling organic reagents, such as 
<smiles>Cc1ccc(O)cc1</smiles><smiles>CCNCCCOC(=O)c1ccc(C(=O)[O-])cc1</smiles>

(MB-OH)<smiles>Cc1ccc2c(c1)CN(CCOC(=O)c1ccc(C(=O)OCCN3COc4ccc(C)cc4C3)cc1)CO2</smiles><smiles>CCC=CC(C)(C)N(C)Cc1cc(C)cc(C)c1O</smiles><smiles>C=CC(CN(CCCOC(=O)c1ccc(C(=O)OCCN(CC(C)=C(C)O)CC(C)(C)C)cc1)Cc1cc(C)cc(C(=O)OCCC)c1O)=C(C)C</smiles>

Scheme 1 Synthetic route to TMBE and PTMBE.

dichloromethane, chloroform, and tetrahydrofuran. Finally, PTMBE was formed by the cross-linking of TMBE under thermal curing reaction with polymerization temperature of $180^{\circ} \mathrm{C}$.

\subsection{Characterization of TMBE}

The chemical structure of TMBE was confirmed by NMR and FTIR spectral analysis. As can be seen from Fig. 1 where the ${ }^{1} \mathrm{H}$ NMR spectrum of TMBE is presented, the appearance of the protons resonating at $4.05 \mathrm{ppm}\left(-\mathrm{O}^{-}{ }^{*} \mathrm{CH}_{2}-\mathrm{N}\right)$ and $4.88 \mathrm{ppm}(\mathrm{Ar}-$ ${ }^{*} \mathrm{CH}_{2}-\mathrm{N}$ ) was clear evidence for the benzoxazine ring formation on TMBE. Moreover, the peaks at $3.18 \mathrm{ppm}$ and $4.52 \mathrm{ppm}$ assigned to protons of $-\mathrm{N}-{ }^{*} \mathrm{CH}_{2}-\mathrm{C}-$ and $\mathrm{C}-{ }^{*} \mathrm{CH}_{2}-\mathrm{O}-$ were observed, respectively. The integral ration of these peaks was close to the theoretical ratio of $2: 2: 2: 2$. The signal peak appeared at $2.27 \mathrm{ppm}$ corresponding to the $\mathrm{Ph}-{ }^{*} \mathrm{CH}_{3}$. The peak appeared at $8.10 \mathrm{ppm}$ corresponding to the protons of the benzene ring linked to the ester group. The peaks appeared at
$6.68 \mathrm{ppm}, 6.75 \mathrm{ppm}$, and $6.95 \mathrm{ppm}$ assigned to protons of benzene ring linked to the oxazine ring.

The ${ }^{13} \mathrm{C}$ NMR spectrum presented from Fig. 2 further proved the structure of TMBE. The carbon resonances of the oxazine ring at $50.7 \mathrm{ppm}$ for $\mathrm{Ar}-{ }^{*} \mathrm{CH}_{2}-\mathrm{N}$ and at $82.9 \mathrm{ppm}$ for $\mathrm{O}-{ }^{*} \mathrm{CH}_{2}-\mathrm{N}$ were clearly observed, respectively. The carbon resonances at 50.38 and $63.65 \mathrm{ppm}$ of $\mathrm{N}-{ }^{*} \mathrm{CH}_{2}-\mathrm{C}$ and $\mathrm{C}-{ }^{*} \mathrm{CH}_{2}-\mathrm{O}$ were clearly appeared, respectively. The peak at 165.71 and $20.30 \mathrm{ppm}$ were characteristic absorptions of $\mathrm{O}-\mathrm{C}^{*}=\mathrm{O}$ and $\mathrm{Ph}-{ }^{*} \mathrm{CH}_{3}$, respectively. The resonance at 128.46 and $133.96 \mathrm{ppm}$ corresponded to carbon atoms in the aromatic ring of terephthalate. Others were characteristic absorptions attributed to the aromatic ring of benzoxazine.

FT-IR spectra also give evidence for the formation of benzoxazine containing bis-ester groups (Fig. 3). The characteristic peak at $932 \mathrm{~cm}^{-1}$ due to the $\mathrm{C}-\mathrm{H}$ out-of-plane vibration in the benzene ring where an oxazine ring attached was clearly observed. Additionally, the strong peak at $1720 \mathrm{~cm}^{-1}$ was characteristic absorption of the carbonyl in terephthalate.

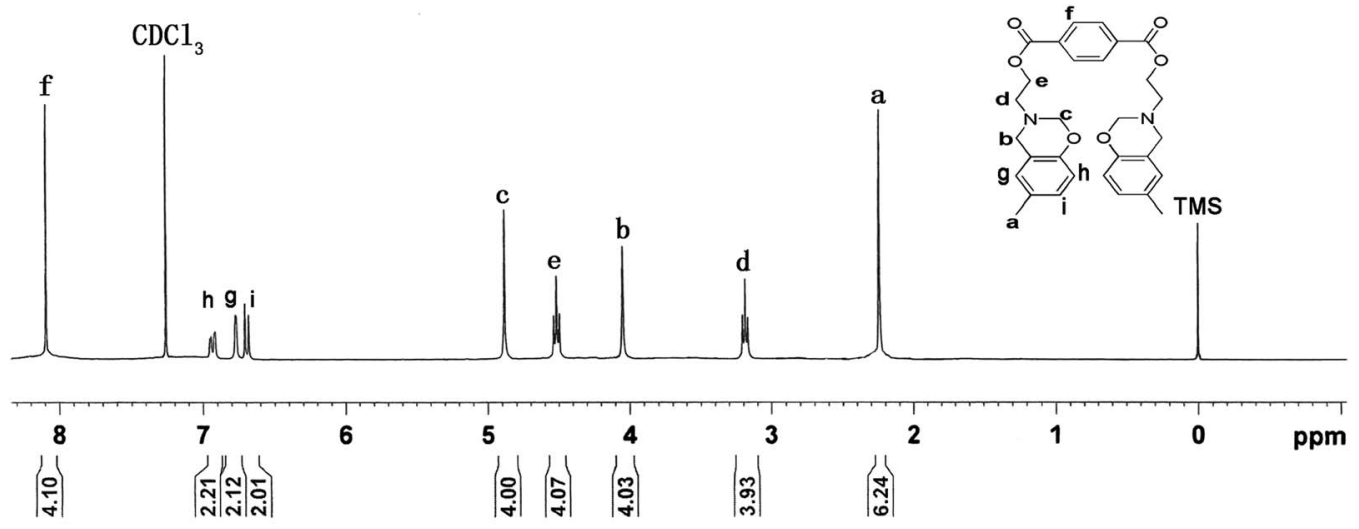

Fig. $1{ }^{1} \mathrm{H}$-NMR spectrum of TMBE. 


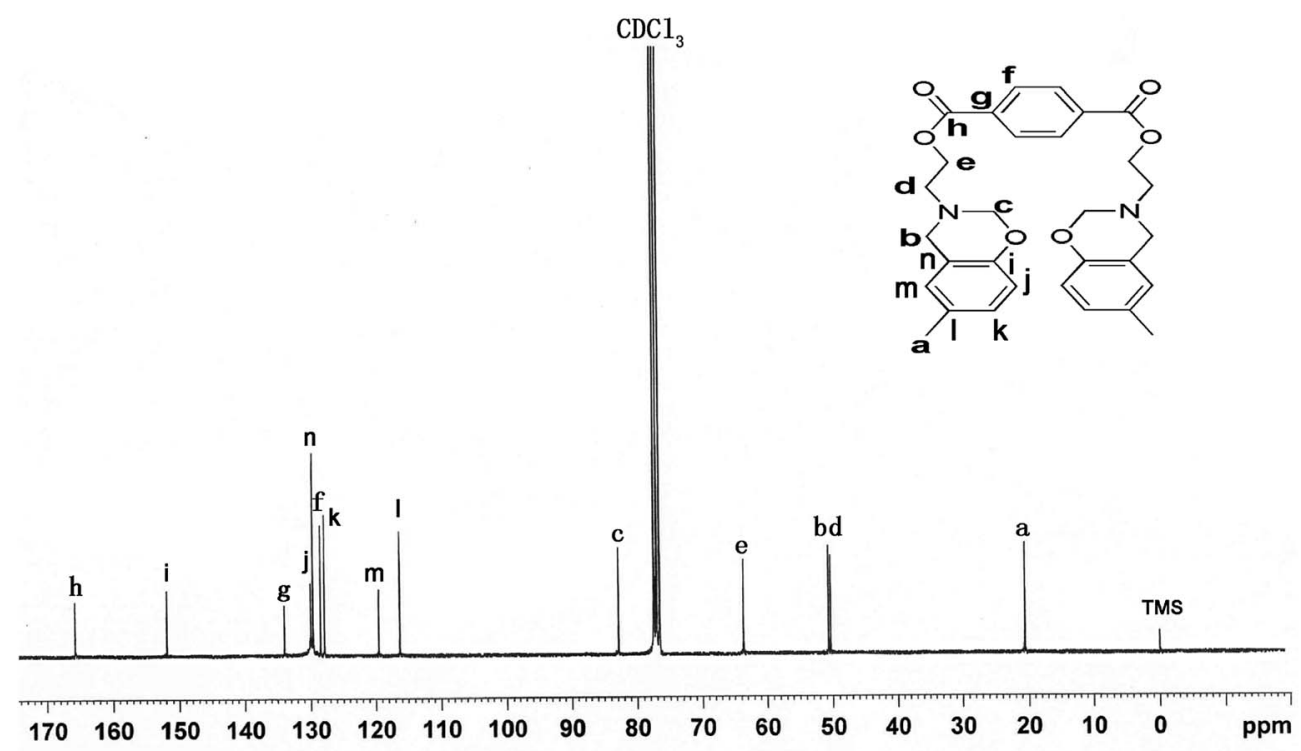

Fig. $2{ }^{13} \mathrm{C}-\mathrm{NMR}$ spectrum of TMBE.

\subsection{Polymerization of TMBE}

The DSC heating-scan thermogram of TMBE was depicted in Fig. 4. The sharp endothermic peak appearing at $139{ }^{\circ} \mathrm{C}$ corresponds to the melting temperature $\left(T_{\mathrm{m}}\right)$ of TMBE. TMBE showed unimodal curing behaviour as observed from the single exothermic peak, which is from the ring-opening polymerization of the benzoxazine ring. The onset and peak top temperatures of the peak are 176 and $231{ }^{\circ} \mathrm{C}$, respectively. The polymerization temperature of TMBE is similar to the values reported to other traditional benzoxazine compounds. ${ }^{30}$ DSC result of curing TMBE show the presence of aliphatic chains (C4) in the benzoxazine structure has little effect on the polymerization behavior of TMBE and only a lower temperature is required for polymerization.

The polymerization behavior of TMBE was also monitored by FTIR after curing at each temperature (Fig. 5). With the increase

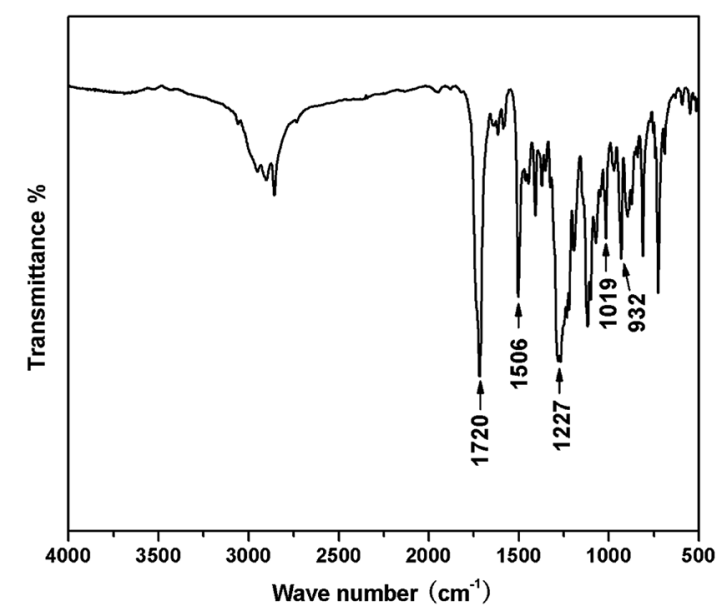

Fig. 3 FTIR spectrum of the TMBE. of temperature, the intensity of the characteristic absorption peak at $932 \mathrm{~cm}^{-1}$ due to benzoxazine structure gradually decreased due to the opening of the oxazine ring and disappeared after the $180^{\circ} \mathrm{C}$ for $2.5 \mathrm{~h}$. The intensity of absorption bands at $1502 \mathrm{~cm}^{-1}$ due to the trisubstituted benzene ring (stretching) also decreased. Meanwhile, some new absorption bands appeared at $3442 \mathrm{~cm}^{-1}$ due to the phenolic hydroxy and at $1481 \mathrm{~cm}^{-1}$ due to the tetrasubstituted benzene ring, suggesting that the ring-opening polymerization of TMBE occurred. Both DSC and IR spectroscopy indicates the formation of polybenzoxazine by polymerization at $180{ }^{\circ} \mathrm{C}$.

\subsection{Thermal property of PTMBE}

Dynamic mechanical analysis (DMA) was performed to study the viscoelastic properties of PTMBE (Fig. 6). At 30 and $80{ }^{\circ} \mathrm{C}$, the storage modulus $\left(G^{\prime}\right)$ values are 168 and $100 \mathrm{MPa}$, respectively, whereas the loss modulus $\left(G^{\prime \prime}\right)$ values are 11 and $27 \mathrm{MPa}$,

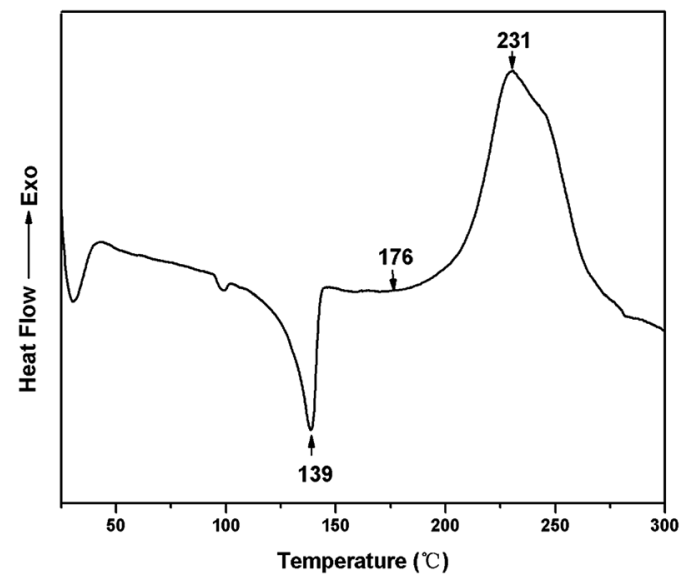

Fig. 4 DSC thermogram of TMBE. 


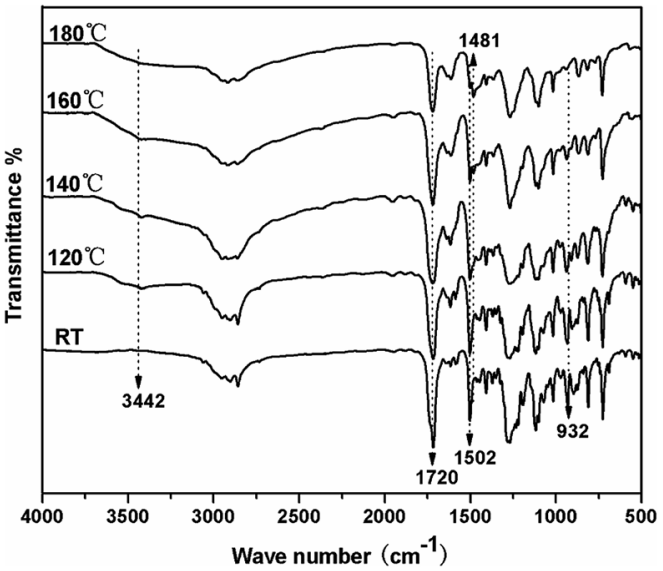

Fig. 5 FTIR spectra of TMBE after curing at each temperature.

respectively. For poly(BA-a) (bisphenol-A and aniline-based polybenzoxazine), the storage modulus $G^{\prime}$ of $1.9 \times 10^{3} \mathrm{MPa}$ is higher than that of PTMBE due to their high aromatic content. It has been clearly demonstrated from DMA that the flexibility of PTMBE is better than poly(BA-a). The $T_{\mathrm{g}}$ was observed at 110 and $89{ }^{\circ} \mathrm{C}$ from the maximum loss factor and maximum loss modulus, respectively. The decrease of $T_{\mathrm{g}}$ can be attributed to the flexible alkyl chain in PTMBE because of a lower energy barrier for motion.

TGA was performed to determine the thermal stability of PTMBE. Fig. 7 shows the TGA thermograms of PTMBE. In nitrogen, 5 and $10 \%$ weight loss temperatures $\left(T_{\mathrm{d} 5}\right.$ and $\left.T_{\mathrm{d} 10}\right)$ of PTMBE were 263 and $289{ }^{\circ} \mathrm{C}$, respectively. The char yield of PTMBE was up to $27.0 \%$ at $800{ }^{\circ} \mathrm{C}$. The $T_{\mathrm{d} 5}$ and $T_{\mathrm{d} 10}$ of PTMBE were decreased by about $50^{\circ} \mathrm{C}$ compared with poly(BA-a). The char yield of PTMBE at $800^{\circ} \mathrm{C}$ has a slight drop compared with poly(BAa). PTMBE shows the lower thermal stability than poly(BA-a) attributed as mentioned previously to the flexible aliphatic chain.

\subsection{Mechanical properties of PTMBE}

The stress-strain curve was showed to study the mechanical property for the PTMBE film (Fig. 8). The PTMBE film showed

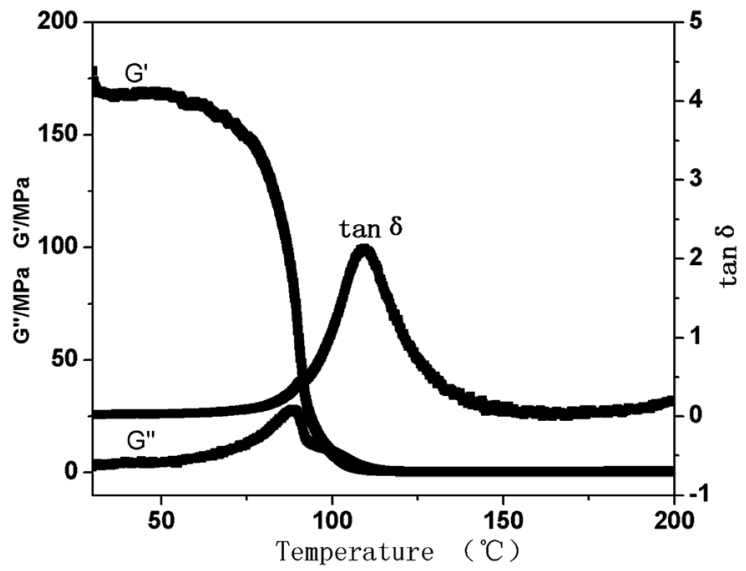

Fig. 6 DMA curves of PTMBE.

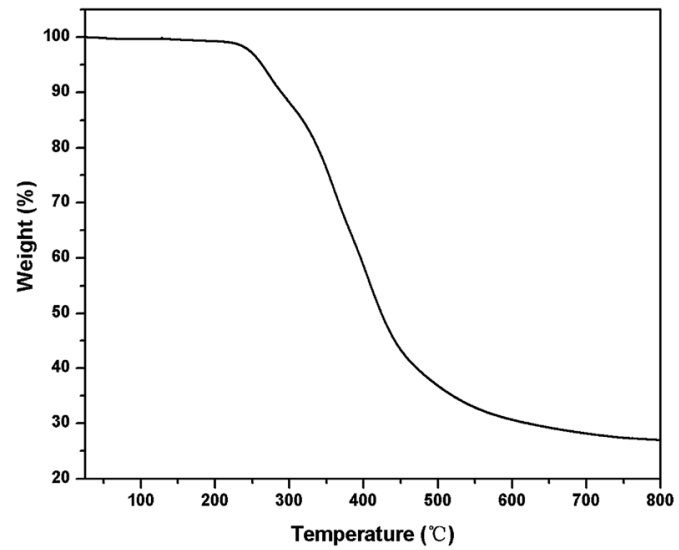

Fig. 7 TGA curve of PTMBE.

elongation at a break of $14.2 \%$ and the tensile strength of 11.3 MPa. It is reported that the PB-a film is very brittle with elongation at break of $1.3 \% .^{30}$ The elongation at break of PTMBE was larger than that of PB-a. Namely, PTMBE had remarkably improved toughness, and the film is easy to bend. Interestingly, in spite of the introduction of the aromatic ester group, PTMBE still showed the high elongation at break comparing with polybenzoxazines ${ }^{\mathbf{2 0}}$ only containing linear long aliphatic chains (C12). The toughness enhancement of PTMBE is attributed to the long flexible alkyl chains, which enhances the mobility of segments under load and thereby increases the ultimate elongation. The tensile modulus of PTMBE is 248.0 MPa, lower than that of PBA-a (4.3 GPa) with rigid backbone. ${ }^{30}$ Therefore, the incorporation of the long aliphatic chain and aromatic ester group into PTMBE network structure gave flexible polymer film without excessively scarifying its heat resistance.

A yellowish PTMBE film $\left(7 \times 6 \mathrm{~cm}^{2}\right)$ with $150-200 \mu \mathrm{m}$ in thickness was obtained through the thermal casting method in Fig. 9(a). A larger-sized film $\left(20 \times 20 \mathrm{~cm}^{2}\right)$ was also prepared in our lab according to the same procedure. Besides, the PTMBE film had remarkably improved toughness, and is easy to bend in Fig. 9(b).

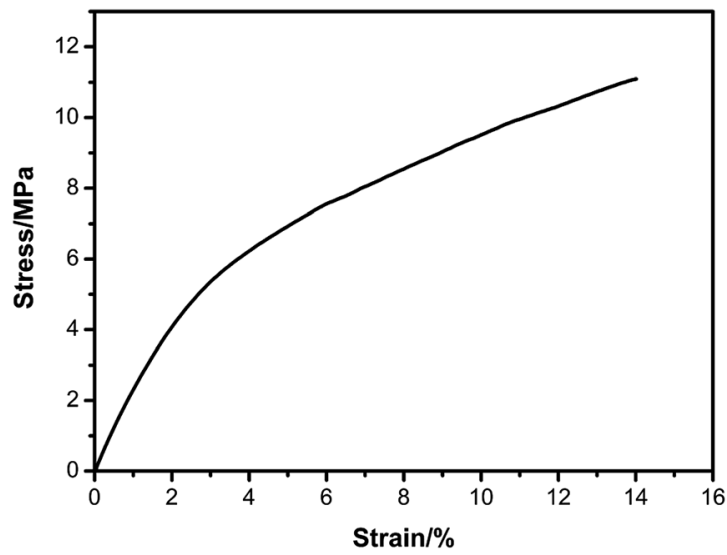

Fig. 8 Stress-strain curve of PTMBE. 


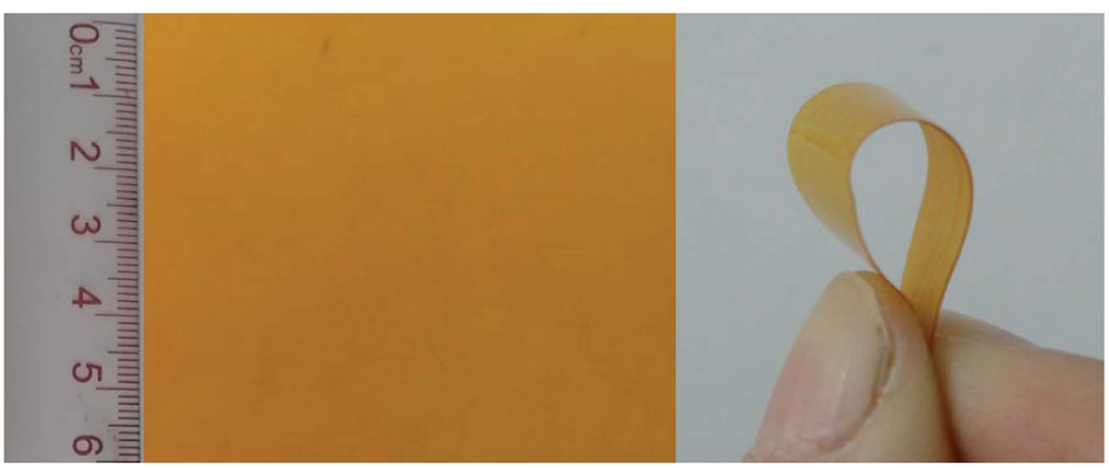

(a)

(b)

Fig. 9 Appearance of PTMBE film (a) and (b).

\section{Conclusions}

By utilizing a clean and facile route, we have prepared a highpurity aromatic ester-based benzoxazine monomer and its polymer. Thermally activated polymerization of benzoxazine monomer provided flexible, uniform polymer film. The novel polybenzoxazine film exhibited significantly improved toughness due to the long aliphatic chain. The storage modulus and glass transition temperature of PTMBE were $168 \mathrm{MPa}$ and $110{ }^{\circ} \mathrm{C}$, respectively. Regarding thermal stability, PTMBE showed lower thermal stability than poly(BA-a) due to the aliphatic hydrocarbon chain. It is anticipated to find applications of PTMBE as a self-healing material.

\section{Conflicts of interest}

There are no conflicts to declare.

\section{Acknowledgements}

The authors are thankful for the financial supports from Shandong Provincial Natural Science Foundation, China (ZR2018MB022).

\section{References}

$1 \mathrm{X}$. Ning and H. Ishida, Phenolic materials via ring-opening polymerization of benzoxazines: effect of molecular structure on mechanical and dynamic mechanical properties, J. Polym. Sci., Part B: Polym. Phys., 1994, 32, 921-927.

2 M. Goto, Y. Miyagi, M. Minami and F. Sanda, Synthesis and crosslinking reaction of polyacetylenes substituted with benzoxazine rings: thermally highly stable benzoxazine resins, J. Polym. Sci., Part A: Polym. Chem., 2018, 56, 18841893.

3 S. Gao, Y. Liu, S. Y. Feng and Z. J. Lu, Synthesis of borosiloxane/polybenzoxazine hybrids as highly efficient and environmentally friendly flame retardant materials, $J$. Polym. Sci., Part A: Polym. Chem., 2017, 55, 2390-2396.
4 H. Xu, W. Zhang, Z. Lu and G. Zhang, Synthesis and properties of thermosetting resin based on urushiol, $R S C$ Adv., 2013, 3, 3677-3682.

5 N. N. Ghosh, B. Kiskan and Y. Yagci, Polybenzoxazines-new high performance thermosetting resins: synthesis and properties, Prog. Polym. Sci., 2007, 32, 1344-1391.

6 Y. Gu and Q. C. Ran, in Handbook of Benzoxazine Resins, ed. H. Ishida and T. Agag, Elsevier, Amsterdam, ch. 28, 2011, pp. 481-494.

7 M. Xu, M. Liu, S. Dong and X. Liu, Design of low temperature self-cured phthalonitrile-based polymers for advanced glass fiber composite laminates, J. Mater. Sci., 2013, 48, 81088116.

8 T. Takeichi, Y. Guo and T. Agag, Synthesis and characterization of poly(urethane-benzoxazine) films as novel type of polyurethane/phenolic resin composites, $J$. Polym. Sci., Part A: Polym. Chem., 2000, 38, 4165-4176.

9 T. Takeichi, T. Kano and T. Agag, Synthesis and thermal cure of high molecular weight polybenzoxazine precursors and the properties of the thermosets, Polymer, 2005, 46, 1217212180.

10 A. Chernykh, T. Agag and H. Ishida, Synthesis of linear polymers containing benzoxazine moieties in the main chain with high molecular design versatility via click reaction, Polymer, 2009, 50, 382-390.

11 B. Kiskan, Y. Yagci and H. Ishida, Synthesis, characterization, and properties of new thermally curable polyetheresters containing benzoxazine moieties in the main chain, J. Polym. Sci., Part A: Polym. Chem., 2008, 46, 414-420.

12 M. Baqar, T. Agag, H. Ishida and S. Qutubuddin, Poly(benzoxazine-co-urethane)s: a new concept for phenolic/urethane copolymers via one-pot method, Polymer, 2011, 52, 307-317.

13 A. D. Baranek, L. L. Kendrick, J. Narayanan, G. E. Tyson, S. Wand and D. L. Patton, Flexible aliphatic-bridged bisphenol-based polybenzoxazines, Polym. Chem., 2012, 3, 2892-2900.

14 A. Tuzun, B. Kiskan, N. Alemdar, A. T. Erciyes and Y. Yagci, Benzoxazine containing polyester thermosets with improved 
adhesion and flexibility, J. Polym. Sci., Part A: Polym. Chem., 2010, 48, 4279-4284.

15 B. S. Rao and A. Palanisamy, A new thermoset system based on cardanol benzoxazine and hydroxy benzoxazoline with lower cure temperature, Prog. Inorg. Chem., 2012, 74, 427434.

16 T. Agag, S. Y. An and H. Ishida, 1,3-bis(benzoxazine) from cashew nut shell oil and diaminodiphenyl methane and its composites with wood flour, J. Appl. Polym. Sci., 2013, 127, 2710-2714.

17 Y. P. Chen, A. Q. Dayo and W. B. Liu, Synthesis of cardanolbased phthalonitrile monomer and its copolymerization with phenol-aniline-based benzoxazine, J. Appl. Polym. Sci., 2019, 136, 47505-47513.

18 A. B. Rajput, S. J. Rahaman, G. Sarkhel, M. K. Patra, S. R. Vadera, P. M. Singru, Y. Yagci and N. N. Ghosh, Synthesis, characterization, and properties of flexible magnetic nanocomposites of cobalt ferritepolybenzoxazine-linear low-density polyethylene, J. Appl. Polym. Sci., 2012, 128, 3726-3733.

19 S. Li, T. Zou, L. Feng, X. Liu and M. Tao, Preparation and properties of cardanol-based polybenzoxazine $/ \mathrm{SiO}_{2}$ hybrids by sol-gel technique, J. Appl. Polym. Sci., 2012, 128, 41644171.

20 D. J. Allen and H. Ishida, Physical and mechanical properties of flexible polybenzoxazine resins: effect of aliphatic diamine chain length, J. Appl. Polym. Sci., 2006, 101, 27982809.

21 T. Agag, L. Jin and H. Ishida, A new synthetic approach for difficult benzoxazines: preparation and polymerization of 4, 4'-diaminodiphenyl sulfone-based benzoxazine monomer, Polymer, 2009, 50, 613-626.

22 T. Agag, A. Akelah, A. Rehab and S. Mostafa, Flexible polybenzoxazine thermosets containing pendent aliphatic chains, Polym. Int., 2012, 61, 124-128.
23 D. B. Austin, L. K. Laken, N. Jananee, E. T. Ginger, W. Steven and L. P. Derek, Flexible aliphatic-bridged bisphenol-based polybenzoxazine, Polym. Chem., 2012, 3, 2892-2898.

24 T. Agag, S. Geiger, S. M. Alhassan, S. Qutubuddin and H. Ishida, Low-Viscosity Polyether-Based Main-Chain Benzoxazine Polymers: Precursors for Flexible Thermosetting Polymers, Macromolecules, 2010, 43, 71227127.

25 T. Takeichi, T. Kano, T. Agag, T. Kawauchi and N. Furukawa, Preparation of high molecular weight polybenzoxazine prepolymers containing siloxane unites and properties of their thermosets, J. Polym. Sci., Part A: Polym. Chem., 2010, 48, 5945-5952.

26 B. Gacal, L. Cianga, T. Agag, T. Takeichi and Y. Yagci, Synthesis and characterization of maleimide (Co)polymers with pendant benzoxazine groups by photoinduced radical polymerization and their thermal curing, J. Polym. Sci., Part A: Polym. Chem., 2007, 45, 2774-2786.

27 C. I. Chou and Y. L. Liu, High performance thermosets from a curable Diels-Alder polymer possessing benzoxazine groups in the main chain, J. Polym. Sci., Part A: Polym. Chem., 2008, 46, 6509-6517.

28 K. D. Demir, B. Kiskan, S. S. Latthe, A. L. Demirel and Y. Yagci, Thermally curable fluorinated main chain benzoxazine polyethers via Ullmann coupling, Polym. Chem., 2013, 4, 2106-2114.

29 B. Aydogan, D. Sureka, B. Kiskan and Y. Yagci, Polysiloxanecontaining benzoxazine moieties in the main chain, J. Polym. Sci., Part A: Polym. Chem., 2010, 48, 5156-5162.

30 T. Agag and T. Takeichi, Synthesis and characterization of novel benzoxazine monomers containing allyl groups and their high performance thermosets, Macromolecules, 2003, 36, 6010-6017. 